\title{
Antibiotics alone versus appendectomy to treat uncomplicated acute appendicitis in adults: what do meta-analyses say?
}

\author{
Leonardo Lima Rocha ${ }^{1,2}$, Felipe Martin Bianco Rossi ${ }^{3}$, Camila Menezes Souza Pessoa ${ }^{1}$, Flavia Nunes Dias Campos ${ }^{1}$,
} Carlos Eduardo Fonseca Pires ${ }^{3}$ and Milton Steinman ${ }^{2,3^{*}}$

\begin{abstract}
Background: Primary appendectomy is the current standard of care for treating uncomplicated acute appendicitis, but interest in conservative treatment with antibiotics alone has been increasing in recent years. Clinical trials so far have shown controversial results.

Methods: A series of meta-analyses were reviewed. Studies comparing surgery versus antibiotics alone for treating uncomplicated acute appendicitis in adults were included. Descriptive statistics and data on treatment effects were retrieved and summarized.

Results: The conservative approach has a success rate of around $60 \%$ and is associated with shorter pain duration, reduced analgesic medication, faster resolution of the inflammation process, lower expenses and quicker return to work. On the other hand, medical treatment leads to high (up to $20 \%$ ) readmission rates and more often requires surgery. An operative approach is associated with higher treatment success rates (>90 \%) and very a low mortality rate.
\end{abstract}

Conclusion: Based on the current body of evidence, the use of antibiotics for primary treatment of uncomplicated acute appendicitis cannot be routinely recommended. Appendectomy remains the gold-standard treatment.

Keywords: Appendicitis, Appendectomy, Antibiotics, Conservative, Surgery, Meta-analysis

\section{Introduction}

Acute appendicitis is the most common cause of inflammatory acute abdomen [1]. The incidence of acute appendicitis varies from 250,000 to 280,000 cases per year in the United States, which accounts for more than 1 million hospital days per year [2] and a cost of more than 3 billion dollars [3]. For more than a century, acute appendicitis has been treated by surgery, i.e., appendectomy $[4,5]$, with mortality rates as low as 0.07 to $0.7 \%$ $[6,7]$. Nevertheless, surgical intervention is associated with greater pain, adherence and hernia development, ileus, venous thromboembolic events, cardiopulmonary complications and increased costs.

\footnotetext{
* Correspondence: milton.steinman@einstein.br

${ }^{2}$ Telemedicine Service, Hospital Israelita Albert Einstein, Av. Albert Einstein, 2 andar, bloco D, São Paulo CEP: 05651-901, Brazil

${ }^{3}$ Surgery Department, Hospital Israelita Albert Einstein, São Paulo, Brazil

Full list of author information is available at the end of the article
}

During the 1950s, an initial non-operative approach for acute appendicitis was attempted, but it was not generally accepted at the time [8]. Appendicitis complicated by appendicular abscess/phlegmon may be managed with antibiotics and non-operative strategies with reduced complication rates compared to surgery [9], like other acute inflammatory intestinal conditions - i.e. diverticulitis and enterocolitis [10]. In this sense, antibiotic therapy may be associated with reduced costs of treatment, avoiding operation and its consequent complications. However, the use of antibiotics alone as primary therapy for uncomplicated acute appendicitis is still being assessed, and studies have shown conflicting results so far $[11,12]$.

The aim of this study is to review available metaanalyses comparing antibiotics alone versus appendectomy for uncomplicated acute appendicitis in adults.

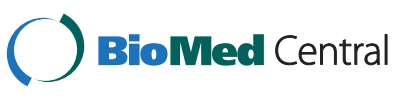

(c) 2015 Rocha et al. Open Access This article is distributed under the terms of the Creative Commons Attribution 4.0 International License (http://creativecommons.org/licenses/by/4.0/, which permits unrestricted use, distribution, and reproduction in any medium, provided you give appropriate credit to the original author(s) and the source, provide a link to the Creative Commons license, and indicate if changes were made. The Creative Commons Public Domain Dedication waiver (http://creativecommons.org/publicdomain/zero/1.0/) applies to the data made available in this article, unless otherwise stated. 


\section{Materials and methods Study selection}

We included all meta-analyses with retrospective or prospective observational and/or experimental studies and compared clinical (antibiotics alone) versus surgical (open or laparoscopic appendectomy) treatment for suspected uncomplicated acute appendicitis in adults ( $>18$ yearsold). Uncomplicated acute appendicitis was defined as acute inflammation of the appendix in the absence of an abscess, phlegmon, free perforation or peritonitis. We excluded meta-analyses enrolling patients with complicated appendicitis, without quality evaluation of individual studies, and children.

\section{Search strategy}

We searched MEDLINE, Embase, and The Cochrane Library databases up to June 2015 for meta-analysis in adults without language restrictions. The following $\mathrm{MeSH}$ (Medical Subject Headings) terms were used: "appendicitis", "meta-analysis", "appendectomy", and "anti-bacterial agents" with Boolean terms. The "related article" function and article references were searched to add other eligible meta-analyses. Experts in the field were also consulted for suggestions on further studies.

\section{Data extraction}

Two different authors (L.L.R. and F.M.B.R.) independently performed the search and retrieved eligible metaanalyses based on previously set inclusion and exclusion criteria. In case of no two authors consensus, a third one (M.S.) was contacted. The data extracted from each study included: first author, year of publication, geographic region, number and design of studies included, inclusion and exclusion criteria, studied population characteristics, statistical analysis (e.g. data on treatment effect, random and/or fixed models; heterogeneity), primary and secondary outcomes and study limitations.

\section{Statistical analysis}

Descriptive statistics summarizing the included studies were calculated. The mean \pm standard deviation was used for normally distributed continuous variables. The median and interquartile range was used for nonnormally distributed continuous variables. Odds ratio and $95 \%$ confidence interval were calculated for specific outcomes from data available in the individual studies whenever not directly calculated by the meta-analysis authors. The meta-analysis pooled results, including the measures of central tendency and measures of treatment effect plus their associated $95 \%$ confidence interval (CI) and $p$-value when available, were extracted and summarized. Ratios were calculated between appendectomy and antibiotics alone groups whenever applicable.

\section{Results}

A total of eight meta-analyses were retrieved [11, 13-19] and their general characteristics are shown in Table 1. The mean number of pooled patients included in each meta-analysis was $862 \pm 211$, which accounts for a mean of $403 \pm 74$ patients in the primary antibiotic therapy group and a mean of $458 \pm 163$ patients in the primary appendectomy group. The mean number of studies included was $4.38 \pm 1.07$. Generally, the quality of the individual studies was deemed low to moderate by different scales. From all the meta-analyses included, there were eight different individual studies, in different combinations

Table 1 Characteristics of included meta-analyses comparing antibiotics alone versus appendectomy in patients with acute uncomplicated appendicitis

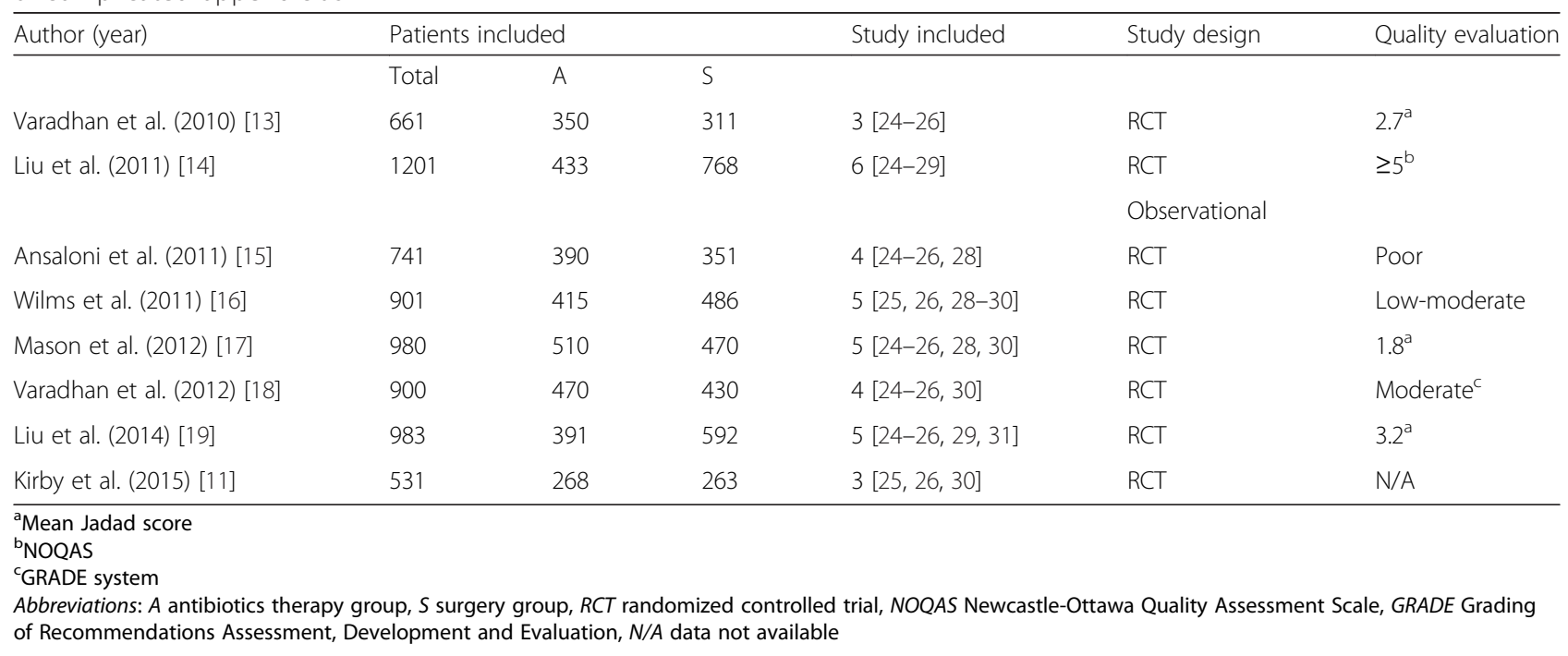


[20-27], with the majority being prospective studies $(87.5 \%)$. Only one meta-analysis included a retrospective study [23].

The main outcome metrics of each meta-analysis are illustrated in Table 2. Conservative therapy with antibiotic therapy was associated with significantly reduced minor (i.e. superficial wound infection, prolonged postoperative course, diarrhea, Clostridium difficile infection, fungal infection, etc.) and major (i.e. abscess formation, peritonitis, deep wound infection, reoperation, small bowel obstruction, postoperative cardiac events and venous thromboembolism) complication rates in most meta-analyses. The exception was the study by Kirby et al. [11], which reported a risk ratio of 7.71 (95\% CI 2.33, 25.53) for major complications (i.e. peritonitis or abscess after the primary intervention) in patients assigned to antibiotic groups.

The conservative treatment was associated with faster recovery from inflammatory response, as evaluated by a better temperature curve, neutrophils count and Creactive protein levels. Also, patients treated with antibiotics alone experienced significantly less pain duration and analgesic medication consumption. Regarding the return to daily activities, patients treated with antibiotics alone had a faster return to work (WMD, -5.20 95\%CI $-6.99,-3.40$ days; $p<0.001)$ and less sick leave duration (MD, -0.19 95\%CI $-0.33,-0.06 ; p=0.005$ ). At the 1 -year follow-up, there was no significant difference between groups in terms of perforation rates $(10.6 \%$ versus $9.3 \% ; p=\mathrm{NS})[11]$.

Table 2 Measured outcomes from different meta-analyses comparing appendectomy versus antibiotics alone for acute uncomplicated appendicitis

\begin{tabular}{|c|c|c|c|c|}
\hline Outcome & Measure of Effect $(95 \% \mathrm{Cl})$ & $p$-value & Heterogeneity & Authors' conclusion \\
\hline \multirow[t]{7}{*}{ Complications } & $0.43(0.15,1.21)[13]$ & 0.11 & Moderate & \\
\hline & $0.31(0.19,0.49)[14]$ & $<0.05$ & Not present & \\
\hline & $1.92(1.30,2.85)[15]$ & N/A & Not present & \\
\hline & $0.83(0.72,0.91)[16]$ & N/A & Low & Favors antibiotics \\
\hline & $0.54(0.37,0.78)[17]$ & 0.001 & Moderate & \\
\hline & $0.69(0.54,0.89)[18]$ & 0.004 & Not present & \\
\hline & $0.86(0.59,1.26)[19]$ & 0.44 & Not present & \\
\hline \multirow[t]{4}{*}{ Treatment efficacy } & $4.54(3.02,6.82)[13]$ & $<0.001$ & N/A & \\
\hline & $6.01(4.27,8.47)[15]$ & N/A & Not present & Favors surgery \\
\hline & Crosses NI margin [16] & N/A & N/A & \\
\hline & $8.89(5.94,13.32)[18]$ & $<0.001$ & N/A & \\
\hline \multirow[t]{2}{*}{ Treatment failure } & $6.9 \% \pm 4.4 \%[14]$ & $\mathrm{N} / \mathrm{A}$ & $\mathrm{N} / \mathrm{A}$ & Favors surgery \\
\hline & $6.72(3.48,12.99)[17]$ & $<0.001$ & Moderate & \\
\hline \multirow[t]{3}{*}{ Readmissions } & $15 \%[13]$ & & & \\
\hline & $14.2 \pm 10.6 \%[14]$ & & & Favors surgery \\
\hline & $20 \%$ [18] & & & \\
\hline \multirow[t]{3}{*}{ Complicated appendicitis } & $0.46(0.19,1.12)[18]$ & 0.09 & High & \\
\hline & $0.58(0.18,1.90)[18]$ & 0.37 & Moderate & Inconclusive \\
\hline & $0.73(0.29,1.84)[15]$ & $\mathrm{N} / \mathrm{A}$ & Not present & \\
\hline \multirow[t]{3}{*}{ Pain/Analgesia } & ATB less pain [15] & $<0.001$ & N/A & \\
\hline & $-1.55(-1.96,-1.14)[17]$ & $<0.001$ & Not present & Favors antibiotics \\
\hline & $-0.13(-0.28,0.03)[17]$ & 0.11 & Low & \\
\hline \multirow[t]{5}{*}{ Length of hospital stay } & $0.11(-0.22,0.43)[13]$ & 0.53 & Moderate & \\
\hline & $0.66(0.44,0.87)[15]$ & $<0.001$ & Low & \\
\hline & $0.34(-0.06,0.73)[17]$ & 0.09 & Low & Inconclusive \\
\hline & $0.34(-0.19,0.87)[18]$ & 0.20 & Low & \\
\hline & $0.01(-0.01,0.03)[19]$ & 0.26 & High & \\
\hline \multirow[t]{2}{*}{ Time to return to work } & $-0.19(-0.33,-0.06)[17]$ & 0.005 & Not present & Favor antibiotics \\
\hline & $-5.20(-6.99,-3.40)[19]$ & $<0.001$ & High & \\
\hline
\end{tabular}


Comparing treatment efficacy, appendectomy was significantly more efficient than antibiotics alone (OR, 6.01 $95 \%$ CI $4.37,8.46)$ when overall treatment was analyzed. Comparing cure up to 1 year, the comparison was inconclusive according to a $20 \%$ non-inferiority margin set by Wilms et al. [16] For the first 24 to $48 \mathrm{~h}$ (6.9 \% versus $7.3 \%$ ) and initial hospitalization (OR, 2.43 95\%CI 0.94, 6.33; $p=0.07$ ), both treatments were equivalent in terms of treatment failures. On the other hand, exclusive antibiotic therapy was associated with a higher rate of readmission, which varied between 14.2 and $20 \%$. And from these readmissions, the absolute majority of patients were treated by the surgical approach, with a second course of antibiotics used in only a few cases (data not shown).

In the majority of meta-analyses, the length of hospital stay was not significantly different between the two groups (Table 2). The exception was the meta-analysis by Wilms et al. [16], which concluded that patients submitted to appendectomy had a reduction of $34 \%$ in their length of hospital stay compared to conservative therapy (OR, 0.66 95\%CI 0.44, 0.87).

The meta-analysis by Ansaloni et al. [15] was the only one that addressed costs. In this study, conservative therapy was associated with a mean cost reduction of USD 1257 per patient treated (USD 2893 versus USD 4150).

\section{Discussion}

To the best of our knowledge, this is the first study to assess a series of meta-analyses comparing appendectomy to antibiotics for uncomplicated acute appendicitis. The results of our review of this series of meta-analyses showed that conservative treatment with antibiotics for uncomplicated acute appendicitis is associated with less complications, faster recovery from an inflammatory state, shorter pain duration and reduced consumption of analgesic medication, faster return to work and reduced costs. Conversely, conservative treatment is associated with significantly higher treatment failure and readmission rates compared to primary appendectomy.

Treating appendicitis implies understanding acute appendicitis as a spectrum of disease, ranging from mild spontaneous resolution cases (up to $20 \%$ ) [28] through perforation and generalized peritonitis. In this sense, the actual challenge is to distinguish those patients who will spontaneously resolve the inflammatory state from those who will develop complications (gangrene, abscess, perforation and peritonitis). Some studies attempted to determine the risk factors for complicated appendicitis [29-31]. The main risk factors associated with complicated appendicitis are clinical (i.e. male sex, age $\geq 60$ years of age and onset of symptoms) and laboratorial (i.e. leukocytosis, elevated C-reactive protein and bilirubin).
Imaging investigations may improve diagnosis, avoiding conservative treatment of patients with complicated appendicitis [32].

CT scan, US and clinical exam, or a combination of these were used to diagnosis uncomplicated acute appendicitis. The CT scan in acute appendicitis has the highest diagnostic sensitivity and specificity, [28] increasing the appendectomy rate, especially in patients with lower Alvarado score [33, 34]. On the other hand, it is related to radiation exposure. The use of combined clinical scores (i.e. Alvarado score and Appendicitis Inflammatory Response score) allied with rational use of imaging methods (i.e. no routine use of CT scan, US in most cases) showed to be nearly as reliable as CT scan for diagnosis of acute appendicitis [35].

Antibiotics success rates as primary therapy for uncomplicated acute appendicitis varied from 58.3 to $73.4 \%$. As much as $42 \%$ of patients primarily treated with antibiotics will require appendectomy later on in the disease's course [13]. Treating patients with uncomplicated appendicitis initially with antibiotics is safe even if an appendectomy is required later [36]. The use of prophylactic antibiotics during appendectomy is associated with a 3-fold reduction in the incidence of wound infection after appendectomy [37]. In the included studies, the surgical wound infection rate in patients undergoing primary appendectomy was $2.8 \%$ when antibiotic prophylaxis was employed and $11.8 \%$ when it was not $[20,26]$. This may have introduced a bias in the metaanalyses that used wound infection as a primary outcome [18], since studies that did not use prophylactic antibiotics may be prone to favor the conservative treatment group [21]. Another issue is the use of heterogeneous antibiotic schemes, which includes oral, intravenous or mixed courses and mono/multi drug therapy. Some antibiotic schemes, such as amoxicillin plus clavulanic acid for Escherichia coli, may be ineffective for treating common gastrointestinal tract bacteria.

Open appendectomy, albeit largely performed worldwide, is associated with longer pain duration and analgesic consumption, longer time to return to work and sick leave, and higher rates of wound infection compared to laparoscopic appendectomy [38]. Patients were submitted to open appendectomy in the majority of studies included. This may have contributed to the significant differences in pain and analgesic consumption, time to work and wound infection rates observed between antibiotics and surgery groups.

All the studies suffered from several methodological limitations and the majority of the outcomes studied in individual meta-analyses presented some degree of heterogeneity, making it challenging to draw definitive conclusions. The study by Hansson et al. [20] showed a very high crossover rate $(47.5 \%)$ mainly from antibiotics to 
the appendectomy group, this might have introduced bias to meta-analyses, which includes this study. Due to the reduced number of enrolled patients, no subgroup analyses were performed to account for possible confounders such as sex, age, diagnostic assessment, surgical procedure (open versus laparoscopic), and use of prophylactic antibiotics to cite a few. Additionally, unblinded outcome assessment may overestimate the effects of treatment and lack of allocation concealment may have introduced selection bias to the analysis.

The recently published APPAC randomized clinical trial [36] was a well-designed adequately powered noninferiority study comparing antibiotics (ertapenem for 3 days plus levofloxacin and metronidazole for 7 days) to appendectomy. It included in the primary analysis 272 patients in the appendectomy group and 256 in the antibiotic therapy group. The primary endpoint for surgery (successful completion of appendectomy) occurred in $99.6 \%$ (95\%CI $98 \%, 100 \%)$ and the primary endpoint for antibiotic therapy group (discharge from hospital without need for appendectomy and no recurrent appendicitis within 1-year follow-up) occurred in $72.7 \%$ (95\%CI $66.8 \%, 78 \%$ ). The difference between treatments was $-27 \%(95 \% \mathrm{CI}-31.6 \%, \infty ; p=0.89)$, which crossed the non-inferiority margin of $24 \%$. The rate of complicated appendicitis did not differ between groups, and the antibiotics group presented lower complication rates. The length of stay was significantly higher in the antibiotics group, though not clinically significant. The ASAA (www.clinicaltrials.gov, NCT01421901) is another well-designed study whose findings will be published soon. The inclusion of these studies in future metaanalyses will help improve the methodological quality and robustness of the results.

\section{Conclusion}

Appendectomy is considered the gold standard for treating uncomplicated acute appendicitis. Nevertheless, for a selected subgroup of patients with no risk factors for complicated appendicitis and/or high surgical risk, conservative therapy with antimicrobials may be safe and effective. The decision to treat patients with acute uncomplicated appendicitis must be made on an individual basis and these patients may be followed closely.

\footnotetext{
Abbreviations

Cl: Confidence interval; CT: Computed tomography; GRADE: Grading of Recommendations Assessment, Development and Evaluation; LOS: Length of stay; MD: Mean difference; N/A: Data not available; NI: Non-inferiority; NS: Not statistically significant; NOQAS: Newcastle-Ottawa Quality Assessment Scale; OR: Odds ratio; RCT: Randomized controlled trial; RR: Risk ratio; US: Ultrasonography; WMD: Weighted mean difference.
}

\section{Competing interests}

All authors declare no conflicts of interest related to this manuscript.

\section{Authors' contributions}

L.L.R. and M.S. were responsible for the study concept and design. L.L.R. and F.M.B.R. carried out the literature search. All authors were involved in acquisition of data from the individual meta-analyses included. L.L.R. and M.S. were responsible for analysis and interpretation of data. L.L.R. drafted the manuscript and performed the statistical analysis. All authors critically reviewed the manuscript for important intellectual content. M.S. was the study supervisor. All authors read and approved the final version of the manuscript.

\section{Acknowledgements}

We are indebted to Mario de Almeida Correia for critically reviewing this manuscript and James Joseph Hesson for English review.

\section{Financial support}

None.

\section{Author details}

${ }^{1}$ Intensive Care Unit, Hospital Israelita Albert Einstein, São Paulo, Brazil. ${ }^{2}$ Telemedicine Service, Hospital Israelita Albert Einstein, Av. Albert Einstein, 2 andar, bloco D, São Paulo CEP: 05651-901, Brazil. S Surgery Department, Hospital Israelita Albert Einstein, São Paulo, Brazil.

Received: 17 June 2015 Accepted: 23 October 2015

Published online: 31 October 2015

\section{References}

1. Humes DJ, Simpson J. Acute appendicitis. BMJ. 2006;333:530-4.

2. Addiss DG, Shaffer N, Fowler BS, Tauxe RV. The epidemiology of appendicitis and appendectomy in the United States. Am J Epidemiol. 1990;132:910-25.

3. Davies GM, Dasbach EJ, Teutsch S. The burden of appendicitis-related hospitalizations in the United States in 1997. Surg Infect (Larchmt). 2004;5:160-5.

4. Fitz RH. Perforating inflammation of the vermiform appendix. Am J Med Sci. 1886;92:321-46

5. McBurney C. Experiences with early operative interference in cases of disease of the vermiform appendix. N Y Med J. 1889;50:1676-84.

6. Blomqvist $P$, Ljung H, Nyren O, Ekbom A. Appendectomy in Sweden 1989-1993 assessed by the Inpatient Registry. J Clin Epidemiol. 1998:51:859-65.

7. Margenthaler JA, Longo WE, Virgo KS, Johnson FE, Oprian CA, Henderson WG, et al. Risk factors for adverse outcomes after the surgical treatment of appendicitis in adults. Ann Surg. 2003;238:59-66.

8. Coldrey E. Five years convervative treatment of acute appendicitis. J Int Coll Surg. 1959;32:255-61.

9. Simillis C, Symeonides P, Shorthouse AJ, Tekkis PP. A meta-analysis comparing conservative treatment versus acute appendectomy for complicated appendicitis (abscess or phlegmon). Surgery. 2010;147:818-29.

10. Wong WD, Wexner SD, Lowry A, Vernava 3rd A, Burnstein M, Denstman F, et al. Practice parameters for the treatment of sigmoid diverticulitissupporting documentation. The Standards Task Force. The American Society of Colon and Rectal Surgeons. Dis Colon Rectum. 2000;43:290-7.

11. Kirby A, Hobson RP, Burke D, Cleveland V, Ford G, West RM. Appendicectomy for suspected uncomplicated appendicitis is associated with fewer complications than conservative antibiotic management: a meta-analysis of post-intervention complications. J Infect. 2015;70:105-10.

12. Mason RJ. Surgery for appendicitis: is it necessary? Surg Infect (Larchmt). 2008:9:481-8.

13. Varadhan KK, Humes DJ, Neal KR, Lobo DN. Antibiotic therapy versus appendectomy for acute appendicitis: a meta-analysis. World J Surg. 2010;34:199-209

14. Liu K, Fogg L. Use of antibiotics alone for treatment of uncomplicated acute appendicitis: a systematic review and meta-analysis. Surgery. 2011;150:673-83.

15. Ansaloni L, Catena F, Coccolini F, Ercolani G, Gazzotti F, Pasqualini E, et al. Surgery versus conservative antibiotic treatment in acute appendicitis: a systematic review and meta-analysis of randomized controlled trials. Dig Surg. 2011;28:210-21.

16. Wilms IM, de Hoog DE, de Visser DC, Janzing HM. Appendectomy versus antibiotic treatment for acute appendicitis. Cochrane Database Syst Rev. 2011;11:CD008359. 
17. Mason RJ, Moazzez A, Sohn H, Katkhouda N. Meta-analysis of randomized trials comparing antibiotic therapy with appendectomy for acute uncomplicated (no abscess or phlegmon) appendicitis. Surg Infect (Larchmt). 2012;13:74-84.

18. Varadhan KK, Neal KR, Lobo DN. Safety and efficacy of antibiotics compared with appendicectomy for treatment of uncomplicated acute appendicitis: meta-analysis of randomised controlled trials. BMJ. 2012;344:e2156.

19. Liu ZH, Li C, Zhang XW, Kang L, Wang JP. Meta-analysis of the therapeutic effects of antibiotic versus appendicectomy for the treatment of acute appendicitis. Exp Ther Med. 2014;7:1181-6.

20. Hansson J, Korner U, Khorram-Manesh A, Solberg A, Lundholm K. Randomized clinical trial of antibiotic therapy versus appendicectomy as primary treatment of acute appendicitis in unselected patients. Br J Surg 2009;96:473-81.

21. Styrud J, Eriksson S, Nilsson I, Ahlberg G, Haapaniemi S, Neovius G, et al. Appendectomy versus antibiotic treatment in acute appendicitis. a prospective multicenter randomized controlled trial. World J Surg. 2006;30:1033-7.

22. Eriksson S, Granstrom L. Randomized controlled trial of appendicectomy versus antibiotic therapy for acute appendicitis. Br J Surg. 1995;82:166-9.

23. Liu K, Ahanchi S, Pisaneschi M, Lin I, Walter R. Can acute appendicitis be treated by antibiotics alone? Am Surg. 2007;73:1161-5.

24. Malik AA, Bari SU. Conservative management of acute appendicitis. J Gastrointest Surg. 2009;13:966-70.

25. Turhan AN, Kapan S, Kutukcu E, Yigitbas H, Hatipoglu S, Aygun E. Comparison of operative and non operative management of acute appendicitis. Ulus Travma Acil Cerrahi Derg. 2009;15:459-62.

26. Vons C, Barry C, Maitre S, Pautrat K, Leconte M, Costaglioli B, et al. Amoxicillin plus clavulanic acid versus appendicectomy for treatment of acute uncomplicated appendicitis: an open-label, non-inferiority, randomised controlled trial. Lancet. 2011;377:1573-9.

27. Gibeily GJ, Ross MN, Manning DB, Wherry DC, Kao TC. Late-presenting appendicitis: a laparoscopic approach to a complicated problem. Surg Endosc. 2003;17:725-9.

28. Cobben LP, de Van Otterloo AM, Puylaert JB. Spontaneously resolving appendicitis: frequency and natural history in 60 patients. Radiology. 2000;215:349-52. 28. Paulson EK, Kalady MF, Pappas TN (2003) Clinical practice. Suspected appendicitis. N Engl J Med 348: 236-242.

29. Barreto SG, Travers E, Thomas T, Mackillop C, Tiong L, Lorimer M, et al. Acute perforated appendicitis: an analysis of risk factors to guide surgical decision making. Indian J Med Sci. 2010;64:58-65.

30. Sheu BF, Chiu TF, Chen JC, Tung MS, Chang MW, Young WR. Risk factors associated with perforated appendicitis in elderly patients presenting with signs and symptoms of acute appendicitis. ANZ J Surg. 2007;77:662-6.

31. McGowan DR, Sims HM, Zia K, Uheba M, Shaikh IA. The value of biochemical markers in predicting a perforation in acute appendicitis. ANZ J Surg. 2013;83:79-83.

32. Nomura O, Ishiguro A, Meakawa T, Nagai A, Kuroda T, Sakai H. Antibiotic administration can be an independent risk factor for therapeutic delay of pediatric acute appendicitis. Pediatr Emerg Care. 2012;28:792-5.

33. Petrosyan M, Estrada J, Chan S, Somers S, Yacoub WN, Kelso RL, et al. CT scan in patients with suspected appendicitis: clinical implications for the acute care surgeon. Eur Surg Res. 2008;40:211-9.

34. Alvarado A. A practical score for the early diagnosis of acute appendicitis. Ann Emerg Med. 1986;15:557-64.

35. Saverio D, Sibilio A, Giorgini E, Biscardi A, Villani S, Coccolini F, et al. The NOTA Study (Non Operative Treatment for Acute Appendicitis): prospective study on the efficacy and safety of antibiotics (amoxicillin and clavulanic acid) for treating patients with right lower quadrant abdominal pain and long-term follow-up of conservatively treated suspected appendicitis. Ann Surg. 2014;260:109-17.

36. Salminen P, Paajanen $H$, Rautio T, Nordström P, Aarnio M, Rantanen T, et al. Antibiotic therapy vs appendectomy for treatment of uncomplicated acute appendicitis: the APPAC randomized clinical trial. JAMA. 2015;313:2340-8.

37. Andersen BR, Kallehave FL, Andersen HK. Antibiotics versus placebo for prevention of postoperative infection after appendicectomy. Cochrane Database Syst Rev. 2005;20:CD001439.

38. Sauerland S, Jaschinski T, Neugebauer EA. Laparoscopic versus open surgery for suspected appendicitis. Cochrane Database Syst Rev. 2010;10:CD001546.

\section{Submit your next manuscript to BioMed Central and take full advantage of:}

- Convenient online submission

- Thorough peer review

- No space constraints or color figure charges

- Immediate publication on acceptance

- Inclusion in PubMed, CAS, Scopus and Google Scholar

- Research which is freely available for redistribution

Submit your manuscript at www.biomedcentral.com/submit 